\title{
Ação repelente, inseticida e fagoinibidora de extratos de pimenta dedo-de-moça sobre o gorgulho do milho
}

\author{
Pepper extracts as a repellent, insecticide and anti-feeding activity on the \\ maize weevil
}

\author{
Sabrina Santos Guimarães ${ }^{1}$, Michele Potrich ${ }^{1 *}$, Everton Ricardi Lozano da Silva ${ }^{1}$, Jônatas Wolf ${ }^{1}$, \\ Carla Samanta Pegorini ${ }^{1}$, Thiego Matheus de Oliveira'
}

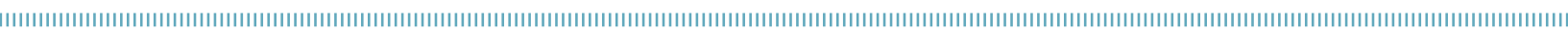

\begin{abstract}
RESUMO: O objetivo deste trabalho foi avaliar o efeito repelente, inseticida e fagoinibidor de extratos de pimenta dedo-de-moça Capsicum baccatum (Willd.) Eshb. (Solanaceae) sobre o gorgulho do milho Sitophillus zeamais (Coleoptera: Curculionidae). O efeito repelente/atraente foi avaliado utilizando quatro arenas/repetições, nas quais foram adicionados os extratos vegetais nas concentraçóes 0 ; 2,5; 5; 10 e $20 \%$ e 140 insetos e, após 24 horas, efetuou-se a contagem de insetos. Para a atividade inseticida, em recipientes plásticos, aplicou-se $1 \mathrm{~mL}$ do extrato nas mesmas concentraçôes já descritas sobre insetos adultos e, após agitaçáo de 10 segundos, foram transferidos para placas de Petri, utilizando 4 repetiçôes, com 20 insetos cada. A mortalidade foi avaliada diariamente durante 10 dias. Para o teste de fagoinibição, os insetos avaliados na atividade inseticida foram pesados em balança analítica, sendo utilizados quatro insetos de cada repetição. Verificaram-se que os extratos aquosos de sementes de pimenta apresentaram atividade repelente na concentração de $20 \%$ e apresentaram atividade inseticida independente da concentração. Efeito correlato foi obtido com extratos alcoólicos de frutos, que apresentaram atividade inseticida e fagoinibidora na concentração de $20 \%$. A utilização de extratos vegetais de pimenta dedo-de-moça constitui alternativa de controle sobre o gorgulho do milho.
\end{abstract}

PALAVRAS-CHAVE: Sitophilus zeamais; Capsicum baccatum; controle alternativo; extratos botânicos.

\begin{abstract}
The objective of this study was to evaluate thee repellent, insecticide and anti-feeding effect of red pepper Capsicum baccatum (Willd.) Eshb. (Solanaceae) extracts on the maize weevil Sitophillus zeamais (Coleoptera: Curculionidae). The determination of the repellent effect of plant extracts was assessed using four arenas/replicates in which the extracts were added at concentrations of $0,2.5,5,10$ and $20 \%$ and 140 insects; and 24 hours after, we performed the counting of insects. For the insecticidal activity, in plastic containers, $1 \mathrm{~mL}$ of the extract was applied, at the concentrations previously mentioned, on adult insects; and after stirring for 10 seconds they were transferred to Petri dishes, using four replicates of 20 insects each. Assessment of mortality was performed daily for ten days. To test the antifeeding activity, insects evaluated for insecticidal activity were weighed on an analytical balance, four insects per replicate. It was found that the aqueous extracts of seeds of pepper had repellent activity at a concentration of $20 \%$; and the insecticide activity was independent of concentration. The correlative effect was obtained with fruit alcoholic extracts, which showed insecticidal and anti-feeding activity at a concentration of $20 \%$. The use of red pepper plant extracts could be an alternative to control the maize weevil.
\end{abstract}

KEYWORDS: Sitophilus zeamais; Capsicum baccatum; alternative control; botanical extracts. 


\section{INTRODUÇÃO}

O Brasil destaca-se internacionalmente na produção de gráos e frutas, sendo que no ano de 2010 foi o segundo maior produtor de feijáo e de soja, terceiro de milho e nono de arroz irrigado (FAO, 2012). Esses dados denotam a importância desses produtos na pauta agrícola, tanto para consumo humano quanto para a produçẫo animal.

Entretanto, esses produtos são deterioráveis e necessitam armazenamento que, no entanto, não elimina a possibilidade da deterioração, tanto que, durante esse período, muitos agentes podem auxiliar nesse processo, como micro-organismos, insetos, ácaros, roedores, pássaros e atividades metabólicas da própria semente (Cruz et al., 2008). Dependendo da espécie e das condiçóes de armazenamento, estima-se que a perda fique entre 10 e 40\% do total armazenado (FAO, 2012).

Entre as pragas relacionadas ao armazenamento de grãos destaca-se o gorgulho do milho Sitophilus zeamais Mots. (Coleoptera: Curculionidae) como uma das mais importantes (Almeida et al., 1999; Lorini, 2002), porém, esse mesmo inseto vem ganhando destaque pelos danos ocasionados às frutíferas (em alguns casos chegando ao status de praga primária) (BоттоN et al., 2005a, 2005b). Essa espécie apresenta infestação cruzada, que é a capacidade de infestar os grãos tanto no campo quanto no armazenamento e no produto beneficiado. Somam-se a isso o elevado potencial de multiplicação e a grande quantidade de plantas hospedeiras, como milho, arroz, trigo, cevada, triticale (LoRINI, 2002), maçấ, uva, pêssego, entre outras.

Nesse atinente, o controle desse inseto, considerado praga, ou sua repelência, é ainda uma preocupação, pois em sua maioria, e cada vez mais, esses procedimentos são realizados utilizando produtos fitossanitários sintéticos, aplicados diretamente nos produtos consumidos in natura, como nos frutos, ou destinados ao consumo humano e animal, além de estarem relacionados a uma gama de impactos ambientais. Dados os problemas que esses produtos causam para o ambiente, bem como para a saúde humana, investigaçôes e estratégias recentes para o controle de pragas estáo sendo pesquisadas, em especial com o uso de extratos de plantas, um dos métodos mais sustentáveis e adequados aos objetivos de minimizaçáo de impactos (Salvadores et al., 2007; Parugrug; Roxas, 2008; Castillo-SÁnchez et al., 2010; Lima-MendonÇA et al., 2013; Fernandes; Favero, 2014). Ademais, há evidências de resistência à utilização de inseticidas sintéticos no controle dessa praga (SANTOS et al., 2009).

A utilização de métodos de controle biológico ou de métodos de controle alternativo contempla, nesse sentido, a cobrança exercida pela sociedade por alternativas que viabilizem práticas agrícolas sem impactos negativos sobre a saúde humana, ambiente e recursos naturais. Além desses métodos apresentarem seletividade e baixa toxicidade quando comparados ao controle químico, podem apresentar efeito repelente, quimioesterilizante, fagoinibidor e inseticida, podendo a aplicação ser na forma de pó, extrato ou óleo (Pedotti-Striquer et al., 2006).

Os extratos vegetais são utilizados em práticas agrícolas alternativas, devido à diversidade de compostos encontrados nas plantas, que são facilmente dispersos em meio líquido. Como em todos os vegetais, nas plantas do gênero Capsicum também são encontradas substâncias com atividade inseticida e de repelência, tais como alcaloides, flavonoides, cumarinas, saponinas e óleos essenciais, provenientes do metabolismo secundário (Luz, 2007).

Nesse sentido, estudos com extratos vegetais para o controle de $S$. zeamais tornam-se promissores, pois, além de serem naturais ao ambiente, são menos tóxicos e com decomposição mais rápida. Ainda, são economicamente viáveis e sustentáveis, pois o agricultor normalmente tem esses vegetais na sua comunidade, podendo desenvolver o extrato em sua propriedade. Assim, o objetivo deste trabalho foi avaliar o efeito repelente, inseticida e fagoinibidor de extratos de pimenta dedo-de-moça Capsicum baccatum (Willd.) Eshb. (Solanaceae) sobre o gorgulho do milho $S$. zeamais, alimentados com grăos de arroz.

\section{MATERIAL E MÉTODOS}

Os experimentos foram realizados em laboratório no qual foram empregadas técnicas de avaliação de resposta de $S$. zeamais quando exposto a extratos vegetais com possível atividade inseticida e/ou repelente. Para a composição dos extratos foram utilizados frutos de C. baccatum coletados em dezembro de 2010, no período da manhá, na horta da Universidade Tecnológica Federal do Paraná, Campus Dois Vizinhos.

\section{Preparo dos extratos de C. baccatum}

Os extratos derivados de Solanáceas, como C. baccatum, têm sido obtidos por vários métodos, utilizando substâncias como água (BAstos et al., 2008) e álcool etílico (МаDHumathy et al., 2007). No que concerne à preparaçáo, os extratos foram obtidos por meio de maceração aquosa e alcoólica de fruto inteiro, polpa e sementes de C. baccatum, em 5 concentraçôes $(0 ; 2,5 ; 5 ; 10$ e $20 \%)$. Foram triturados em liquidificador $100 \mathrm{~g}$ do material vegetal (fruto, polpa ou semente), adicionados $500 \mathrm{~mL}$ de água destilada fria ou álcool 92,8\% (comercializado em supermercados), aproximando-se das condiçôes encontradas nas propriedades rurais e de como esses extratos poderiam ser preparados.

As soluçôes permaneceram em repouso, na ausência de luz e sob refrigeração por 24 horas. Posteriormente, as soluçôes foram filtradas, evaporadas e ressuspensas (quando para extratos alcoólicos), sendo armazenadas em recipientes fechados, mantidos sob refrigeração e ao abrigo da luz, até serem 
utilizadas. Essa solução primária correspondeu ao extrato bruto com concentração de $20 \%$. A partir dessa solução foram elaboradas as demais concentraçôes dos extratos (10; 5 e 2,5\%). Como testemunha foi utilizada água destilada esterilizada.

\section{Criação de S. zeamais}

Os insetos foram criados em arroz, acondicionados em recipientes de vidro fechados com tecido tipo voil à temperatura de $26 \pm 3^{\circ} \mathrm{C}$, umidade relativa (UR) de $40 \pm 10 \%$ e fotofase de 12 horas. A cada 15 dias foram efetuados procedimentos de rotina, descartando-se os insetos mortos e separando-se o arroz com as respectivas oviposiçôes. Na sequência, os recipientes foram novamente estocados até a emergência da geração F1 (adaptado de Ротrich et al., 2010).

\section{Teste de atratividade/repelência}

Foi determinado avaliando a atratividade e/ou repelência do inseto pelo extrato aplicado. Para isso, foram usadas arenas, confeccionadas com recipientes plásticos circulares $(30 \mathrm{~cm}$ de diâmetro), contendo uma lâmina de isopor encaixada a $5 \mathrm{~cm}$ do fundo do recipiente, com uma marca central (base para liberação dos insetos) (adaptado de РотRIch et al., 2010).

Em cada arena foram dispostos 7 frascos plásticos $(5 \mathrm{~cm}$ de altura por $3,5 \mathrm{~cm}$ de diâmetro), um para cada tratamento (testemunha, semente de C. baccatum aquoso, semente de C. baccatum alcoólico, polpa de C. baccatum aquoso, polpa de C. baccatum alcoólico, fruto de C. baccatum aquoso e fruto de C. baccatum alcoólico) dentro da concentração, todos equidistantes. Cada frasco recebeu $10 \mathrm{~g}$ de arroz pulverizado com $1 \mathrm{~mL}$ do extrato vegetal a ser testado, sendo a testemunha pulverizada com água destilada esterilizada. Foram avaliados os extratos aquoso e alcoólico de C. baccatum nas concentraçôes de 2,5 e 20\%, sendo que cada concentraçấo compôs uma arena. No centro da arena foram liberados 140 insetos, sendo as arenas vedadas com tecido voil e fita adesiva, para evitar a fuga dos insetos. As arenas foram mantidas em câmara climatizada à temperatura de $26 \pm 3^{\circ} \mathrm{C}$, fotofase 12 horas e UR de $70 \pm 10 \%$. Após 24 horas, o número de insetos em cada um dos recipientes foi quantificado. O delineamento experimental foi em blocos ao acaso, com quatro repetiçóes, sendo cada arena considerada uma repetição.

\section{Teste de atividade inseticida e fagoinibidora}

Os insetos foram colocados em frascos plásticos e acrescidos de $1 \mathrm{~mL}$ de cada concentração dos extratos. Cada frasco foi agitado durante 20 segundos e, posteriormente, os insetos foram transferidos para uma placa de Petri, contendo papel filtro ao fundo e $2 \mathrm{~g}$ de arroz. As placas contendo os insetos foram mantidas em câmara climatizada à temperatura de
$26 \pm 3^{\circ} \mathrm{C}$, fotofase 12 horas e UR de $70 \pm 10 \%$. Foram preparadas 4 repetições para cada tratamento, com 20 insetos adultos cada, em delineamento inteiramente casualizado. A testemunha consistiu da aplicação de água destilada esterilizada. A avaliaçáo de mortalidade foi realizada diariamente durante o período de dez dias (adaptado de Ротrich et al., 2010).

Os insetos do teste de atividade inseticida foram utilizados para o teste de atividade de fagoinibição. Para isso, quatro insetos de cada repetição foram pesados em balança analítica, nos dois últimos dias do experimento de atividade inseticida. Esse procedimento justifica-se na investigação de possíveis alteraçôes no peso dos insetos, o que seria consequência do efeito do extrato sobre a alimentação deles (adaptado de Guzzo et al., 2002; MARSARO JÚNIOR et al., 2005).

Em todos os experimentos, os dados foram submetidos à análise de variância (teste F) e as médias comparadas pelo teste de Tukey a 5\% de probabilidade, com auxílio do programa estatístico Sisvar 5.3 (Ferreira, 2010).

\section{RESULTADOS E DISCUSSÃO}

\section{Teste de atratividade/repelência}

Na concentração de $20 \%$, os extratos aquosos de semente, polpa e fruto não diferiram significativamente da testemunha, porém apresentaram as menores porcentagens médias de atratividade, sendo 6,$0 ; 6,3$ e 6,5\%, respectivamente, caracterizando repelência. O extrato alcoólico da polpa, nessa mesma concentração, apresentou atratividade para adultos de $S$. zeamais, sendo observada porcentagem média de $34,6 \%$ insetos (Tabela 1).

A repelência de extratos do gênero Capsicum a adultos de S. zeamais foi observada com preparados em pó de Capsicum frutescens (Procópio et al., 2003). Frutos de C. baccatum, na concentração de $792 \mathrm{~g} / 0,75 \mathrm{~cm}^{2}$ foram repelentes a Tetranychus urticae (Trombidiformes: Tetranychidae) (ANTONious; SNYDER, 2005) e Capsicum annuum em pó, na concentração de $2 \%$ foi repelente a S. zeamais (Salvadores et al., 2007). O efeito repelente é atribuído aos compostos ativos alcaloides e capsaicina, presentes nas plantas do gênero Capsicum.

Os extratos de C. baccatum na concentração de 2,5\% não diferiram significativamente entre si quanto à repelência à $S$. zeamais no presente trabalho. Esse fato pode estar relacionado aos componentes aromáticos presentes em C. baccatum, que podem ter confundido os adultos de $S$. zeamais (Luz, 2007). Nesse âmbito, substâncias extraídas pelo álcool e, por conseguinte, constantes no extrato alcoólico da polpa a $20 \%$, podem ter atuado de forma atrativa aos insetos, náo estando presentes nos extratos aquosos ou estando presente em pequenas quantias.

Considerando que o extrato alcoólico a $20 \%$ da polpa de C. baccatum atraiu uma grande proporção de insetos, restaram 
poucos para infestar os demais tratamentos, de forma que eles podem ter escapado à infestação, não apresentando um fator de repelência em si para os demais extratos.

\section{Atividade inseticida}

Verificou-se que o extrato de sementes aquoso nas concentraçôes de 2,5; 5 e $20 \%$ provocou mortalidade significativa em adultos de $S$. zeamais. No entanto, os extratos de polpa e de fruto não provocaram mortalidade significativa, não diferindo da testemunha (Tabela 2). O extrato aquoso de semente

Tabela 1. Porcentagem média de atratividade ( \pm erro padrão) de $S$. zeamais a extratos de C. baccatum $\left(26 \pm 3^{\circ} \mathrm{C}\right.$, fotofase 12 horas e umidade relativa de $70 \pm 10 \%)$.

\begin{tabular}{lcc} 
& \multicolumn{2}{c}{$\begin{array}{c}\text { Porcentagem média de } \\
\text { atratividade }\end{array}$} \\
\cline { 2 - 3 } Tratamentos & $\begin{array}{c}\text { Extrato a } \\
2,5 \%\end{array}$ & $\begin{array}{c}\text { Extrato a } \\
20 \%\end{array}$ \\
\hline Testemunha & $25,1 \pm 11,60^{\mathrm{a}}$ & $11,6 \pm 0,00^{\mathrm{bc}}$ \\
\hline Semente de C. baccatum aquoso & $15,2 \pm 5,93^{\mathrm{a}}$ & $6,0 \pm 1,25^{\mathrm{c}}$ \\
\hline Semente C. baccatum alcoólico & $10,1 \pm 3,43^{\mathrm{a}}$ & $15,1 \pm 3,99^{\mathrm{bc}}$ \\
\hline Polpa C. baccatum aquoso & $8,8 \pm 1,89^{\mathrm{a}}$ & $6,3 \pm 0,63^{\mathrm{c}}$ \\
\hline Polpa C. baccatum alcoólico & $15,6 \pm 2,95^{\mathrm{a}}$ & $34,6 \pm 4,85^{\mathrm{a}}$ \\
\hline Fruto C. baccatum aquoso & $14,3 \pm 3,97^{\mathrm{a}}$ & $6,5 \pm 0,71^{\mathrm{c}}$ \\
\hline Fruto C. baccatum alcoólico & $10,5 \pm 3,19^{\mathrm{a}}$ & $17,9 \pm 2,22^{\mathrm{b}}$ \\
\hline Coeficiente de variação (\%) & 40,25 & 40,25
\end{tabular}

a,b,c Médias seguidas pela mesma letra minúscula não diferem entre si pelo teste de Tukey $(p<0,05)$.

Tabela 2. Porcentagem de mortalidade ( \pm erro padrão) de $S$. Zeamais quando tratados com diferentes extratos de $C$. baccatum $\left(26 \pm 2^{\circ} \mathrm{C}\right.$, fotofase 12 horas e umidade relativa de $\left.70 \pm 10 \%\right)$.

\begin{tabular}{|c|c|c|c|}
\hline \multirow{2}{*}{$\begin{array}{c}\text { Concentração } \\
(\%)\end{array}$} & \multicolumn{3}{|c|}{ Aquoso } \\
\hline & Semente & Fruto & Polpa \\
\hline 0 & $2,4 \pm 1,41^{\text {Abns }}$ & $2,4 \pm 1,41^{\text {Aans }}$ & $2,4 \pm 1,41^{\text {Aans }}$ \\
\hline 2,5 & $37,8 \pm 8,04^{\mathrm{Aa}^{*}}$ & $5,2 \pm 2,15^{\mathrm{Ba}^{*}}$ & $11,3 \pm 5,15^{\text {Bans }}$ \\
\hline 5 & $32,4 \pm 9,05^{\mathrm{Aa}^{*}}$ & $10,7 \pm 4,55^{\mathrm{Ba}^{*}}$ & $13,3 \pm 8,52^{\mathrm{ABa}^{*}}$ \\
\hline 10 & $25,9 \pm 15,24^{\text {Aab* }^{*}}$ & ${ }^{*} 12,3 \pm 1,35^{\mathrm{Aa}^{*}}$ & $20,7 \pm 8,23^{\text {Aans }}$ \\
\hline 20 & $33,8 \pm 6,88^{\text {Aans }}$ & $4,9 \pm 3,54^{\mathrm{Ba}^{*}}$ & $8,6 \pm 1,36^{\mathrm{Ba}^{*}}$ \\
\hline \multicolumn{2}{|c|}{ Coeficiente de variação (\%) } & 45,00 & \\
\hline \multirow{2}{*}{$\begin{array}{c}\text { Concentração } \\
\text { (\%) }\end{array}$} & & Alcoc & \\
\hline & Sem & Fruto & Polpa \\
\hline 0 & $2,4 \pm 1,41^{\mathrm{Ab}}$ & $2,4 \pm 1,41^{\mathrm{Ab}}$ & $2,4 \pm 1,41^{A b}$ \\
\hline 2,5 & $13,4 \pm 4,12^{\mathrm{Bab}}$ & $38,9 \pm 10,06^{A a}$ & $18,5 \pm 5,97^{\mathrm{ABab}}$ \\
\hline 5 & $11,0 \pm 4,55^{\mathrm{Bab}}$ & $60,0 \pm 6,46^{\mathrm{Aa}}$ & $36,9 \pm 7,68^{\mathrm{Aa}}$ \\
\hline 10 & $3,8 \pm 1,25^{\mathrm{Bb}}$ & $51,5 \pm 2,95^{\mathrm{Aa}}$ & $24,2 \pm 4,02^{\mathrm{Aa}}$ \\
\hline 20 & $29,2 \pm 7,50^{A a}$ & $37,5 \pm 5,20^{A a}$ & $35,7 \pm 9,16^{\text {Aa }}$ \\
\hline \multicolumn{4}{|c|}{ Coeficiente de variação (\%) } \\
\hline \multicolumn{4}{|c|}{$\begin{array}{l}\text { A,BMédias seguidas pela mesma letra maiúscula na linha não diferem } \\
\text { entre si pelo teste de Tukey }(p<0,05) ; \text {; } \mathrm{ab} \text { médias seguidas pela } \\
\text { mesma letra minúscula na coluna não diferem entre si pelo teste de } \\
\text { Tukey ( } p<0,05) ;{ }^{*} \text { médias seguidas de asterisco diferem entre si } \\
\text { dentro do mesmo extrato e concentração, em diferentes métodos } \\
\text { de obtenção (aquoso e alcoólico); }{ }^{\text {ns }} \text { médias não diferem entre si } \\
\text { dentro do mesmo extrato e concentração, em diferentes métodos de } \\
\text { obtenção (aquoso e alcoólico). }\end{array}$} \\
\hline
\end{tabular}

não apresentou diferenças na mortalidade provocada entre as concentrações avaliadas, direcionando a observação do efeito inseticida à parte da planta utilizada no extrato (semente) e não à concentração.

O fato dos extratos de sementes no meio aquoso aferirem maior efeito inseticida pode ser atribuído à ocorrência dos componentes principais, responsáveis pelas atividades biológicas atribuídas às pimentas, que são os capsaicinoides (até $1 \%$ na matéria seca do fruto), sendo a capsaicina e a dihidrocapsaicina os mais importantes. Os capsaicinoides são produzidos em um tecido interno denominado placenta, ao longo do qual são dispostas as sementes (Luz, 2007), estando, possivelmente, presente nos extratos de sementes.

Comparando-se os extratos aquosos dentro de cada concentração, verificou-se que nas concentraçôes de 2,5 e $20 \%$ o extrato de semente provocou maior mortalidade $(37,8 \mathrm{e}$ $33,8 \%$, respectivamente), diferindo significativamente do extrato de fruto $(5,2$ e $4,9 \%)$ e do extrato da polpa (11,3 e $8,6 \%$ ) (Tabela 2).

$\mathrm{Na}$ avaliação dos extratos alcoólicos de C. baccatum observou-se que o extrato de semente provocou mortalidade significativa em adultos de $S$. zeamais quando aplicado na concentração de $20 \%$, porém, sem diferir das concentraçóes 2,5 e $5 \%$. O extrato de polpa provocou mortalidade significativa nas concentraçóes de 5; 10 e 20\%, sendo superior na primeira concentração (36,9\%). Não obstante, a maior mortalidade foi aferida no extrato alcoólico de frutos 5\% (60\%), sem diferir, contudo, das demais concentrações.

$\mathrm{Na}$ comparação dos extratos alcoólicos dentro de cada concentração, verificou-se que na concentração de $2,5 \%$ o extrato de fruto provocou maior mortalidade $(38,9 \%)$, náo diferindo significativamente do extrato de polpa $(18,5 \%)$. Nas concentraçóes de 5 e $10 \%$ verificaram-se que os extratos de fruto e polpa provocaram os maiores índices de mortalidade de S. zeamais. Entretanto, na concentração de $20 \%$ os extratos não diferiram entre si. Esses dados decorrem da possível interação do meio de extração dos princípios ativos (alcoólico) e a parte da planta, sobrepujando os efeitos dos compostos ativos de Capsicum em detrimento do álcool veiculado no extrato. CAstillo-SANChez et al. (2010), ao reportarem o efeito metabólico de extratos vegetais no controle biológico de insetos, salientaram que um solvente que minimize o impacto sobre o inseto deve ser usado para diluir os extratos nos ensaios.

Comparando os métodos de extração (aquoso e alcoólico) de sementes de C. baccatum, observou-se que o extrato aquoso apresentou maior potencial inseticida, sendo sua atividade significativa nas concentrações de 2,5; 5 e 10\%. O contrário foi observado quando a parte de C. baccatum utilizada foi o fruto, sendo que a extração alcoólica, nas concentraçóes de 2,5; 5 ; 10 e $20 \%$ provocaram a maior porcentagem de mortalidade de S. zeamais. O mesmo ocorreu para o extrato alcoólico de polpa nas concentraçóes de 5 e $20 \%$. 
Lale (1992) verificou o efeito inseticida do óleo e do pó de sementes de Piper guineense Schumach \& Thonn. (Piperaceae) (Pimenta de-são-tomé), Dennettia tripetala G. Barker (Anonaceae) e Aframomum melegueta (Roskoe) K. Schum (Zingiberaceae) (pimenta-da-Guiné), em relação a $S$. zeamais. Efeito inseticida de extratos de frutos de $C$. frutescens sobre Callosobruchus maculatus (Coleoptera: Chrysomelidae) e Sitophilus orizae foram relatados por Gakuru e Foua (1996). Ainda, efeito inseticida dos frutos de C. frutescens sobre Sitophilus orizae e efeito repelente de macerados de folhas sobre $S$. zeamais foram observados por Procópio et al. (2003).

Devem-se considerar as divergências encontradas na literatura para os efeitos de extratos de diferentes espécies de Capsicum sobre insetos, pois o teor de capsaicinoides é avaliado pela escala de unidade de calor Scoville (Scoville Heat Unit - SHU), cujos valores variam de 0 a 300 mil SHU (Reifschneider, 2000). A pungência da espécie $C$. baccatum é baixa, oscilando na escala de 5 a 15 mil SHU e de 5 a 6 na escala de temperatura (Joly, 1998). Tem-se postulado a hipótese para os efeitos discrepantes das espécies de Capsicum.

Os constituintes químicos provenientes do metabolismo secundário de C. baccatum (alcaloides, diterpenoides, flavonoides, compostos fenólicos e saponinas) conferem à planta ação repelente característica. Essas substâncias detêm diferentes graus de polaridade, sendo solúveis em diferentes solventes, o que explica a diferença de concentração de compostos ativos e, consequentemente, de atividade entre os extratos em distintos solventes (aquoso e alcoólico) (Solomons; FryHLe, 2005), bem como pelas metodologias de extração, grau de maturação do fruto e pelas condiçôes ambientais a que a planta foi submetida durante o seu crescimento, tais como temperatura e luminosidade (Iorizzi et al., 2000).
Dentre as substâncias presentes em $C$. baccatum são encontrados alcaloides e saponinas, que são altamente solúveis em água. De acordo com os resultados obtidos com extratos aquosos de semente a 2,5; 5 e 20\%, esses compostos podem estar presentes em maior quantidade nessas concentrações (Luz, 2007). Inferem-se que sejam mais facilmente extraídos quando as sementes estão dispersas na água e, portanto, na ausência da polpa, liberando esses compostos e causando mortalidade significativa nos insetos.

Os compostos fenólicos (incluindo flavonoides) e diterpenoides são mais solúveis em álcool e encontram-se em abundância nos frutos, conferindo-lhes a sensação caústica e sabor picante, sendo assim facilmente extraídos, justificando a atividade inseticida do fruto e da polpa (Simóes et al., 2004; Oliveira; Akisue, 2005; Luz, 2007; Solomons; FryHle, 2005).

\section{Atividade fagoinibidora}

Entre os insetos que se alimentaram de arroz tratado com o extrato aquoso, o melhor resultado foi obtido com o fruto de C. baccatum na concentração de $10 \%$, em que os insetos apresentaram o menor peso $(0,0050 \mathrm{~g})$, quando comparados aos insetos alimentados com os demais tratamentos contendo extratos aquosos nessa mesma concentração. Para o extrato alcoólico, o melhor resultado também foi obtido com o extrato do fruto de C. baccatum, porém, na concentraçáo de $20 \%$, em que os insetos apresentaram peso de $0,0031 \mathrm{~g}$, diferindo significativamente das demais concentraçôes. Para os demais tratamentos (extratos aquosos e alcoólicos de semente e polpa) não houve diferença significativa na atividade fagoinibidora, comparando-se às respectivas testemunhas (Tabela 3).

Tabela 3. Peso médio, em gramas, ( \pm erro padrão) de adultos de $S$. zeamais alimentados com arroz tratado com diferentes extratos de C. baccatum.

\begin{tabular}{|c|c|c|c|}
\hline \multirow{2}{*}{$\begin{array}{l}\text { Concentração } \\
\text { (\%) }\end{array}$} & \multicolumn{3}{|c|}{ Aquoso } \\
\hline & Semente & Fruto & Polpa \\
\hline 0 & $0,0071 \pm 0,0005^{\text {Aa }}$ & $0,0071 \pm 0,0005^{\mathrm{Aa}}$ & $0,0071 \pm 0,0005^{A_{C}}$ \\
\hline 2,5 & $0,0068 \pm 0,0004^{A a}$ & $0,0073 \pm 0,0004^{\mathrm{Aa}}$ & $0,0074 \pm 0,0004^{A_{C}}$ \\
\hline 5 & $0,0078 \pm 0,0002^{\text {Aa }}$ & $0,0071 \pm 0,0008^{\mathrm{Aa}}$ & $0,0068 \pm 0,0006^{A c}$ \\
\hline 10 & $0,0069 \pm 0,0005^{\text {Aa }}$ & $0,0050 \pm 0,0008^{\mathrm{Ba}}$ & $0,0072 \pm 0,0003^{A_{C}}$ \\
\hline 20 & $0,0071 \pm 0,0005^{\text {Aa }}$ & $0,0057 \pm 0,0010^{\mathrm{Aa}^{*}}$ & $0,0074 \pm 0,0003^{A c}$ \\
\hline Coeficiente de variação (\%) & \multicolumn{3}{|c|}{17,99} \\
\hline \multirow{2}{*}{$\begin{array}{l}\text { Concentração } \\
(\%)\end{array}$} & \multicolumn{3}{|c|}{ Alcoólico } \\
\hline & Semente & Fruto & Polpa \\
\hline 0 & $0,0071 \pm 0,0005^{\text {Aa }}$ & $0,0071 \pm 0,0005^{A a}$ & $0,0071 \pm 0,0005^{A_{c}}$ \\
\hline 2,5 & $0,0074 \pm 0,0002^{\text {Aa }}$ & $0,0058 \pm 0,0013^{A a}$ & $0,0073 \pm 0,0003^{A_{C}}$ \\
\hline 5 & $0,0068 \pm 0,0004^{\text {Aa }}$ & $0,0064 \pm 0,0004^{A a}$ & $0,0078 \pm 0,0002^{A c}$ \\
\hline 10 & $0,0065 \pm 0,0008^{\mathrm{Aa}}$ & $0,0064 \pm 0,0017^{A a}$ & $0,0081 \pm 0,0003^{A_{C}}$ \\
\hline 20 & $0,0072 \pm 0,0004^{\text {Aa }}$ & $0,0031 \pm 0,0002^{\mathrm{Bb}}$ & $0,0076 \pm 0,0004^{A c}$ \\
\hline Coeficiente de variação (\%) & \multicolumn{3}{|c|}{17,99} \\
\hline
\end{tabular}

A,BMédias sequidas pela mesma letra maiúscula na linha não diferem entre si pelo teste de Tukey $(p<0,05)$; a,bmédias seguidas pela mesma letra minúscula na coluna não diferem entre si pelo teste de Tukey $(p<0,05)$; *médias seguidas de asterisco diferem entre si dentro do mesmo extrato e concentração. 
Atribui-se a diminuição de peso dos insetos ao efeito fagoinibidor desencadeado pelo extrato, acreditando-se que essa atividade seja consequência dos constituintes da $C$. baccatum, como a capsaicina, presente em abundância nas plantas do gênero Capsicum (Silva et al., 2009), e que pode ter inibido a capacidade sensorial de $S$. zeamais, reduzindo sua alimentação e peso.

Desse modo, os frutos do gênero Capsicum são as partes normalmente utilizadas na tentativa de obtençáo do efeito fagoinibidor para insetos, efeitos atribuídos à presença de capsaicinoides, no entanto, verificam-se que propriedades diferentes são atribuídas à cada parte dessa espécie vegetal.

\section{CONCLUSÃO}

Os extratos aquosos de sementes de pimenta dedo-de-moça apresentam atividade repelente sobre o gorgulho do milho, fator importante para utilização em propriedades rurais, especialmente na fruticultura. Frutos de pimenta dedo-de-moça possuem atividade inseticida tanto na forma de extratos alcoólicos quanto de extratos aquosos. $\mathrm{O}$ gorgulho do milho apresentou inibição da atividade alimentar quando exposto aos extratos aquoso e alcoólico de frutos de pimenta dedo-de-moça, nas concentraçôes de 10 e $20 \%$, respectivamente. Testes de cromatografia para a identificação dos compostos químicos são necessários, bem como testes destes produtos em semicampo e diretamente em frutos.

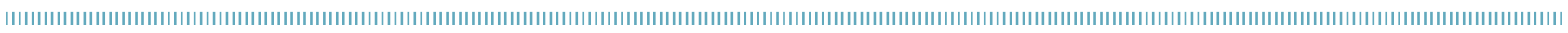

\section{REFERÊNCIAS}

ALMEIDA, F.A.C.; GOLDFARB, A.C.; GOUVEIA, J.P.G. Avaliação de extratos vegetais e métodos de aplicação no controle de Sitophilus spp. Revista Brasileira de Produtos Agroindustriais, v.1, n.1, p.13-20, 1999.

ANTONIOUS, G.F; SNYDER, J.C. Repellency of hot pepper extracts to spider mites. In: ROWELL, B.; SNYDER, J.; SMIGELL C. (eds.). Fruit and Vegetables Crop. Research Report. Agricultural Experiment Station. Kentucky: University of Kentucky-College of Agriculture, 2005. 94p.

BASTOS, S.; SAUSEN, C.; GRENDELE, C.Y.; EGEWARTH, R. Efeito de extratos de plantas com atividade inseticida no controle de Microtheca ochroloma Stal (Col: Chrysomelidae), em laboratório. Revista Biotemas, v.21, n. 1, p.41-46, 2008.

BOTTON, M.; LORINI, I., AFONSO A.P.S. Ocorrência de Sitophilus zeamais Mots. (Coleoptera: Curculionidae) danificando a cultura da videira no Rio Grande do Sul. Neotropical Entomology, v.34, n.2, p.355-356, 2005a.

BOTTON, M.; LORINI, I.; LOECK, A.E.; AFONSO, A.P.S. O gorgulho do milho Sitophilus zeamais (Coleptera: Curculionidae) como praga em frutíferas de clima temperado. Circular Técnico 58. Bento Gonçalves: Embrapa Uva e Vinho, 2005b. 7p.

CASTILLO-SÁNCHEZ, L.E.; JIMÉNEZ-OSORNIO, J.J.; DELGADOHERRERA, M.A. Secondary metabolites of the annonaceae, solanaceae and meliaceae families used as biological control of insects. Tropical and Subtropical Agroecosystems, n. 12, p.445462, 2010.

CRUZ, J.C.; KARAM, D.; MONTEIRO, M.A.R.; MAGALHÃES, P.C. (EDS.). A CULTURA DO MILHO. SETE LAGOAS: EMBRAPA MILHO E SORGO, 2008. 517P.

FAO. FOOD AND AGRICULTURE ORGANIZATION OF THE UNITED NATIONS. Country rank in the world, by commodity. Disponível em: http://faostat.fao.org/site/339/default.aspx. Acesso em: 31 maio 2012.
FERNANDES, E.T.; FAVERO, S. Óleo essencial de Schinus molle L. para o controle de Sitophilus zeamais Most. 1855 (Coleoptera: Curculionidae) em milho. Revista Brasileira de Agroecologia. v.9, n. 1, p.225-231, 2014.

FERREIRA, D.F. Sisvar ${ }^{\circledR}$, versão 5.3. 2010. Disponível em: http:// http://www.dex.ufla.br/ danielff/softwares.htm. Acesso em: 01 ago. 2011.

GAKURU, S.Y.; FOUA, K. Effet d'extraits de plantes sur la bruche du niebe (Callosobruchus maculatus Frab.) et le charancon du riz (Sitophilus oryzae L.). Cahiers Agriculture, v.5, p.39-42, 1996.

GUZZO, E.C.; ALVES, L.F.A.; ZANIN, A.; VENDRAMIN, J.D. Identificação de materiais de milho resistentes ao ataque de gorgulho Sitophilus zeamais (Mots., 1855) (Coleoptera: Curculionidae). Arquivos do Instituto Biológico, v.69, n.2, p.6973, 2002.

IORIZZI, M.; LANZOTTI, V.; TREMATERRA, P.; ZOLLO, F. Chemical components of Capsicum annuum L. var. acuminatum and their activity on stored products insect pests. In: LANZOTTI, V.; TAGLIATERRA-SCAFATI, O. Flavourand fragrance chemistry. Dordrecht: Kluwer Academic Publishers, 2000. p.77-85.

JOLY, A.B. Botânica: introdução à taxonomia vegetal. $12^{\mathrm{a}}$ ed. São Paulo: Companhia Editora Nacional, 1998. 777p.

LALE, N.E.S. A laboratory study of the comparative toxicity of products from three spices to the maize weevil. Postharvest Biology and Technology, v.2, n.1, p.61-64, 1992.

LIMA-MENDONÇA, A.; BROGLIO, S.M.F.; ARAÚJO, A.M.N.; LOPES, D.O.P.; DIAS-PINI, N.S. Efeito de pós vegetais sobre Sitophilus zeamais (Mots., 1855) (Coleoptera: Curculionidae). Arquivos do Instituto Biológico, v.80, n.1, p.91-97, 2013.

LORINI, I. Manejo integrado de pragas de grãos de cereais armazenados. Passo Fundo: Embrapa Trigo, 2002. 72p. 
LUZ, F.J.F. Caracterização morfológica e molecular de acessos de pimenta (Capsicum chinense Jaqc.). 2007. 70p. Tese (Doutorado em Produção Vegetal) - Universidade Estadual Paulista, Jaboticabal, 2007.

MADHUMATHY, A.P; AIVAZI, A-A.; VIJAYAN, V.A. Larvicidal efficacy of Capsicum annum against Anopheles stephensi and Culex quinquefasciatus. Journal of Vector Borne Diseases, v.44, n.9, p.223-226, 2007.

MARSARO JÚNIOR, A.; LAZZARI, S.M.N.; FIGUEIRA, E.L.Z.; HIROOKA, E.Y. Inibidores de amilase em híbridos de milho como fator de resistência a Sitophilus zeamais (Coleoptera: Curculionidae). Neotropical Entomology v.34, n.3, p.443-450, 2005.

OLIVEIRA, F.; AKISUE, G. Fundamentos de farmacobotânica. $2^{a}$ ed. São Paulo: Editora Atheneu, 2005. 178p.

PARUGRUG, M.L.; ROXAS, A.C. Insecticidal action of five plants against maize weevil, Sitophilus zeamais Motsch. (Coleoptera: Curculionidae). KMITL Science Technology Journal, v.8, n. 1, 2008.

PEDOTTI-STRIQUER, L.; BERVIAN, C.I.; BAUNQAERTNER, F.S. Ação repelente de plantas medicinais e aromáticas sobre Sitophilus zeamais (Coleoptera: Curculionidae). Ensaios e Ciência, v. 10, n. 1 , p.55-62, 2006.

POTRICH, M.; ALVES, L.F.A.; MERTZ, N.R.; BONINI, A.K.; SILVA, E.R.L.; MARCHESE, L.P.C. Seleção e associação de cultivares de milho com Beauveria bassiana para o controle de Sitophilus zeamais (Coleoptera: Curculionidae). Semina: Ciências Agrárias, v.31, n. 1, p.5-18, 2010.
PROCÓPIO, S.; VENDRAMIM, J.; RIBEIRO, J.Y.; BARBOSA, J. Bioatividade de diversos pós de origem vegetal em relação a Sitophilus zeamais Mots. (Coleoptera:Curculionidae). Ciência e Agrotecnologia, v.27, p.1231-1236, 2003.

REIFSCHNEIDER, F.J.B. (org.). Capsicum: pimentas e pimentões no Brasil. Brasília: Embrapa comunicação para transferência de tecnologia/Embrapa Hortaliças, 2000. 113 .

SALVADORES, U.Y.; SILVA, A.G.; TAPIA, V.M.; HEPP, G.R. Polvos de especias aromáticas para el control del gorgojo del maíz, Sitophilus zeamais Motschulsky, en trigo almacenado. Agricultura Técnica, v.67, n.2, p.147-154, 2007.

SANTOS, J.C.; FARONI, LR.D.; SIMÕES, R.O.; PIMENTEL, M.A.G.; SOUSA, A.H. Toxicity of pyrethroids and organophosphorus insecticides to Brazilian populations of Sitophilus zeamais (Coleoptera: Curculionidae). Bioscience Journal, v.25, n.6, p.75-81, 2009.

SILVA, D.J.F; SCHERER, B.S.; ALVES, M.K.; SILVA, J.R.O. Determinação do potencial antioxidante do extrato filtrado de Capsicum baccatum (pimenta dedo-de-moça) através do método DPPH. In: X SALÃO DE INICIAÇÃO CIENTÍFICA, 2009, Porto Alegre, RS. Resumos. Porto Alegre: 2009, p.56-58.

SIMÕES, C.M.O.; SCHENKEL, E.P.; GOSMANN, G.; MELLO, J.C.P.; MENTZ, L.A.; PETROVICK, P.R. Farmacognosia: da planta ao medicamento. $5^{\text {a }}$ ed. Porto Alegre/Florianópolis: Editora da UFRGS, 2004. 1102p.

SOLOMONS, T.V.G.; FRYHLE, C.B. Química orgânica. v.2. $8^{\text {a ed. }}$ Rio de Janeiro: LTC, 2005. 588p. 